\title{
Analysis on Educational Thoughts of Tang Junyi*
}

\author{
Tao $\mathrm{Yu}$ \\ Center for Studies of Education and Psychology of \\ Minorities in Southwest China \\ Southwest University \\ Chongqing, China \\ School of Humanities and Management Sciences \\ Sichuan Medical University \\ Luzhou, China
}

\author{
Yuan Zhang \\ Ideological and political Department \\ Sichuan Medical University \\ Luzhou, China
}

\begin{abstract}
Moral self" is the theoretical basis of Professor TangJunyi's ideas on education, all of Tang's views about education is the result of reconstruction of the ideal moral-self. To achieve this ideal, Tang thought that education should promote the ascension of personality of the educators and the educatees at the same time, and the ascension of personality should not be separated from daily life of the educates, but comply with the educatees' personality and the welldevelopment of both body and mind. The school education, especially the humanities education in nowadays could learn something good from New Asia College, such as the general education, tutorial system and so on. And the fundamental object we draw lessons from New Asia College should be its idea about promoting the ascension of personality of educators and educatees together.
\end{abstract}

Keywords-TangJunyi; education; moral self; New Asia College

\section{INTRODUCTION}

As an important representative of New Confucianism, Tang Junyi (1909-1978) had a lot of masterpieces. Although he had no specific works on pedagogy, nor proposed any systematic educational theories, his practice of humanistic educational thoughts and general education thoughts in New Asia College, possesses important status in current school education in China, especially in the aspects such as improving personalities of educatees and carrying forward Chinese traditional culture.

\section{THE THEORETICAL BASIS OF EDUCATIONAL THOUGHTS OF TANG JUNYI}

Tang Junyi believed that the most fundamental crisis of the Chinese nation was the moral depravity of the public, especially in modern Chinese society, in which the spiritual pillar of the traditional society, namely, Confucian ethical values, encountered unprecedented challenges, the authority of confucian ethical thoughts was almost lost, the new ethical values had not yet been established, the behaviors of the public stayed in "rootless", and the entire society fell into the trouble of moral decline. To this end, he considered that the key point to solve the problem was to reestablish the central concepts supporting the ethnical orders of Chinese society,

The Project Supported by Sichuan Thinkers Research Center.

Corresponding Author: Zhang Yuan, E-mail: 184627669 @q.com that was, the "moral self". This so-called "moral self" is the origin of all human moral values, and can be understood from three aspects [1]: first of all, moral self itself is absolutely good; secondly, moral self determines moral values, while moral values are the expression of moral self; thirdly, moral values are the basis of all human cultural activities, and the level of moral values determines the level of human cultural activities. It is thus clear that "moral self" is the source of all human cultural activities, and governs and guides the cultural activities of human beings. Its position is similar to some concepts in philosophy such as "Logos", "Doctrine" and "Principle".

Therefore, moral self is the one and the first, moral values are the intermediary, while cultural activities are the many, the last. Tang Junyi believed that the development of Chinese culture and even the world culture, were supposed to re-examine the moral self, start from moral self, and blend it into various cultural activities. Only the cultural activities blended with moral self could be continued and developed. In the meantime, he considered that the four cultural activities including sports, military affairs, laws and education had the functions of saving human culture (See Figure 1). Education was to "carry human culture into the future, and develop personality awareness of individuals who created the human culture". Therefore, the education, as a part of human cultural activities, its purpose, contents, and methods exactly should be determined by the level of moral self. All of Tang Junyi's views about education in his writings and educational activities in New Asia College were derived from his ideas to rebuild moral self, that is, to blend the moral self with various cultural activities through education. Therefore, this paper agrees that "moral self" is the theoretical basis of Tang Junyi's educational thoughts, and the blend of moral self with cultural activities is the ultimate goal of his educational thoughts. 


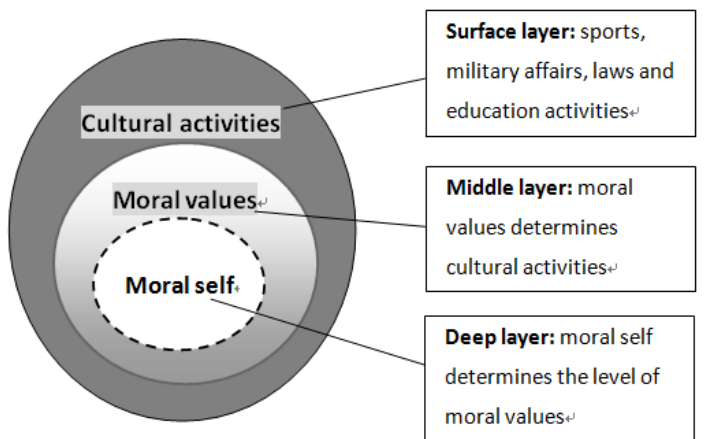

Fig. 1. Diagram of relations among moral self, moral values and cultural activities

\section{THE THEORY OF TANG JUNYI ON EDUCATION PURPOSE}

Tang Junyi in his book "Cultural Awareness and Moral Reason" clearly stated that the purpose of education was to help others improve personalities, thus for the continuation of culture [2]. It consists of two aspects.

\section{A. Help Others to Improve Personality}

Currently, a relatively coherent definition of "personality" is "a kind of persistent self with consistency and continuity in impetus, and individuals' special physical and mental organizations formed in the socialization process" [3]. The scholar, Jing Huaibin, divided Confucian personalities into "benevolence", "manners" and "knowledge", and the intrinsic nature of these three elements was "morality", while the external phenomenon was the "comprehension of own destiny". According to his schematic diagram of Confucian personalities (Figure 2) [4], Confucian personalities upwards can determine the "ultimate values", and downwards can determine the "social functions", while the "improvement of personality" is to preferably play the functions of the personalities both upwards and downwards.

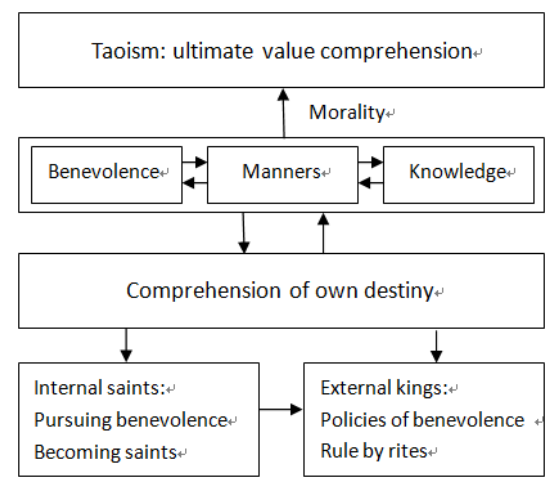

Fig. 2. Schematic diagrams of Confucian personalities

Tang Junyi considered that the key point to promote the improvement of human personality was not the biological instinct. The improvement of individual personality depended on personal moral cultivation, while the improvement of personality of other people lay in the level of education awareness. To this end, Tang Junyi divided education awareness of educators or teachers into five levels [2], and discussed the personalities embodied in educators and educatees in different levels of education awareness. The first was the lowest level of education awareness, in which educators' awareness and behaviors were not regulated by rationality but dominated by their life desire. Under this education awareness, educators were self-centered, and carried out education activities just for themselves. Education was merely a way or a tool for their selffulfillment. Thus, educators' self-awareness influenced the contents, methods and results of education. The second was a higher level of education awareness. In this education awareness, educators taught "valuable" knowledge, skills and virtues they fancied, and considered that educatees should learn these "correct" values and contents. The disadvantage of this education awareness was that educators saw educatees as pure recipients, and were more inclined to the cramming method of teaching. Therefore, the level of educators' values, knowledge and skills determined the level of those of educatees. The third level was a higher level of education awareness than level 2 . It referred to that educators, with selfless hearts, pursued the continuation of culture and taught valuable knowledge, skills or virtues they believed, and in the meantime considered that educatees had the personalities to use reasons to accept culture. Under this education awareness, educators were more focused on understanding the personality, environment and habits of educatees, and were more prone to know about the needs, desires and abilities of educatees, attaching importance to the teaching methods of "individualized". The fourth level was a higher level of education awareness than the previous one. In this level, it is believed that educatees were both the recipients of culture and the creators of culture, and, they were supposed to have awareness of cultural contents beyond their own experience. Therefore, the greatest teachers were those who hoped their students to go beyond them, and the greatest educators were those who expected new generations to be better than the contemporary educators in culture. The fifth level was the highest level. Educators left behind the knowledge and concepts of cultural life they possessed, and felt they seemed to know nothing. The sense of "seemed to know nothing" made educators willing to learn and recognize the values of all external human knowledge and culture. In this education awareness, educators took all people who had created cultures in the past as their teachers, all people who were possible to achieve mutual promotion with them currently as friends, and all future human beings as their students. All human beings constituted a huge education group, whereby the whole natural world became a human world. Therefore, education work should not be only responsible for the human cultural education, but also responsible for the entire universe.

According to the five levels of education awareness, different education awareness in different levels has different positive effects and results on both educators and educatees' personalities. Higher levels of education awareness are more valuable than those of relatively lower levels. Both educators and educatees are meant to continuously go beyond their own moral levels, namely, improving their personalities 
constantly, thus to realize higher levels of education awareness, and form an absolutely good moral self.

\section{B. For the Purpose of Continuation of Human Culture}

Tang Junyi believed that the purpose of education was to help others improve personalities for the continuation of culture. Therefore, helping others to improve personalities is the way to pass down the human culture. "Pass down" includes the preservation of human culture, and also contains the meaning of creating human culture. Tang Junyi considered that the four cultural activities including sports, military affairs, laws and education had the functions of passing down human culture. Sports and military affairs mainly focused on body while education and laws were primarily spiritual. As for the spirit, laws lays emphasis on "preserving the existed human culture, and establishing the awareness to form logical orders of group living of human beings", namely, the function of preserving and transferring human culture. Education focuses on "the continuation of human culture into the future, and developing personality awareness of individuals who created human culture". That is to say, education not only has the mission of passing down and preserving human culture, but more importantly, is to enhance human's personality awareness, thus to promote the development of human culture.

\section{THE THEORY OF TANG JUNYI ON EDUCATIONAL METHODS}

\section{A. Promoting the Improvement of Personalities of both Educators and Educatees}

Tang Junyi believed that our education should firstly enhance educatees' personalities. While at present, our school education is more interested in transferring knowledge and regulating educatees' external behaviors, ignoring the responsibilities to improve educatees' inherent personalities. "Personality" is the link connecting human moral self and their external behaviors, so low-level personalities are caused by the low level of moral values, which is exactly the root of the moral decline of the public. Therefore, the purpose of education is not only to transfer human cultural knowledge, but more importantly, is to improve the level of human personality. In this regard, Tang Junyi thought that the promotion of educatees' personalities was related to the level of educators or teachers' education awareness. Higher-level education awareness develops higher-level personalities, while lower-level education awareness leads to lower-level personalities. So, schools are supposed to focus on training educators to pursue higher levels of education awareness, and improve their personalities in the first place.

\section{B. Cultural Activities should be Linked with Daily Life}

Tang Junyi considered that in the West and modern westernized Chinese cities, people's cultural activities were separated from their daily lives. For example, Westerners went to church for religious rites, went to galleries and concert halls for pursuing arts, went to libraries and schools to seek the truth, and went to gyms and swimming pools for sports. Chinese ancient culture was mostly derived directly from ancestors' labor experience and political lives, and was closely linked with their daily lives, such as China's earliest literary masterpiece, "The Book of Songs". It primarily described the daily lives in the Zhou Dynasty. Confucians advocated that morality was inseparable from daily life, and as they talked that "chopping wood and fetching water are also good ways to cultivate oneself". In other words, eating, dressing, sleeping, and working, all these daily activities were valuable, and could not be merely taken as tools or ways to save lives and races. Therefore, Confucians emphasized daily life and taught people to pay attention to all the things in life. However, the biggest drawback of Western thoughts was that they considered all daily lives as tools or means to pursue spiritual and cultural life. For instance, modern naturalists believed that eating and sex were just for the purpose of meeting people's biological instinctive desires to save lives and races, and to achieve the natural evolution. Tang Junyi saw the difference between Chinese and Western cultures, and considered that if we wanted to improve educators' awareness of education, we could not just seek for the spiritual transcendence while ignoring daily lives. Both of them should be connected, and thus allowed daily life itself to be beautified and artified. That is to say, we should aim at daily lives, and first of all concentrate on the daily lives, and then daily lives will be gradually beautified and artified.

\section{Going along with the Personalities of Educatees as well as their Physical and Mental Development}

Tang Junyi, when served as the dean of students in New Asia College, asked the school to set up a number of elective courses for students, and required students to freely select one course to learn according to their own personal interest, ability and demands. He believed that different from the laws and regulations which required individuals to passively recognize and obey, education awareness needed to be accepted positively by educators. Higher levels of education awareness include both educators' cultural awareness and educatees' natural physiological and psychological awareness. In these levels, educatees play the roles both of cultural recipients and cultural creators, and have the capacity to rationally select education methods and contents. Therefore, in order to achieve higher levels of education awareness, it is necessary to go along with the personalities of educatees as well as their physical and mental development.

\section{Practice OF EdUCATION ThOUGHTS OF TANG JUNYI}

\section{A. Emphasis on General Education}

Tang Junyi stated that "to form a whole personality, the key point is to study general knowledge. Chinese previous ideal scholars were those who had considerable knowledge in culture, history, philosophy, society and nature. I believe that only this kind of scholar is capable to be the true educators or social political leaders" [5]. Thus, since the beginning of New Asia College, it advocated general education. "Studies Regulations in New Asia College" Article IX said: "Based on the accumulation of considerable 
general knowledge, to select a major for further study according to own talent and nature; you are supposed to be a learned person firstly, and then try to be an expert" [6]. The Enrollment Guide of the college in March, 1950 wrote: "All the courses in our college are set giving priority to the general knowledge firstly, and then set for specialty. We focus primarily on the basic training of words, and then involve general cultural courses, helping students to establish a solid foundation of considerable general knowledge, and then, according to their talent and nature, guiding them to find out the means and ways for further study of a variety of specialized knowledge and skills, and trying to make them truly understand the important status and meanings of their specialty in the whole life" [6]. The two pieces of materials above clearly reflected the status of "general education" in New Asia College, and the general education in the college had two features. "First, focus on the common general education courses in all majors (in first and second grade), to cultivate students for sound ideological basis. Therefore, the elementary courses like philosophy, history, psychology, sociology, economics and philology occupy most of their time. Second, set up specialized and technical courses for the third grade. These courses are primarily based on the selfstudy and teachers' instruction, and occupy less time of students compared to the first and second grade" [7]. Thus it can be seen that Tang Junyi attached great importance to general education, and considered general education as the basis for promoting the improvement of students' personalities.

\section{B. Adopting Tutorial System}

Tang Junyi considered that in Chinese ancient society, students generally followed a certain teacher to learn and live, so the teacher's personality and knowledge made great influence on the students. Such education methods had some disadvantages, such as, if teachers didn't possess excellent personality and knowledge, they might restrict the development of their students both in personality and knowledge. While in the West, the school education was totally different from Chinese traditional education methods. In the West, students learned from several teachers, allowing them to integrate the personalities and knowledge of those teachers, and then to form their own personalities and knowledge systems. But, Western school education had high requirements on the comprehensive ability of students. If students could not integrate the personalities and knowledge from several teachers, they were easy to get into mess. The education aims of New Asia College was exactly to try combining the academy spirit from Chinese traditional culture with the tutorial system in modern Western universities, making the best of the both worlds, "hoping to make up for the shortcomings of the course center by personality center" [8], and making every professor in the school to be a personality center. Professors were the persons teaching knowledge, and the models in personality, capable of helping students to make great progress both in personality and knowledge. To this end, in addition to giving common basic lessons, teachers in New Asia College also made a connection with students through tutorial system. That was, "Asking students to select one or two teachers, to get closely connection with them in daily lives and commune with them in spirit. And in the meantime teachers kindly instruct their students with the whole personalities and lifelong knowledge obtained, trying to help them to keep the interest and habits in their studies for further research in future after entering the society" [6] .

\section{Carrying forward Chinese Traditional Cultural Spirit}

In 1959, Hong Kong government planned to change New Asia College into an official university, but Tang Junyi considered that a school controlled by the British government was difficult to maintain its Chinese cultural ideals. Therefore, in the consolidation process, Tang Junyi was always the opponent, and did everything he could to fight for a place for Chinese cultural spirit: firstly, adhering to use the name of "Chinese University of Hong Kong", and hoping the school to keep up the essence of "Chinese" in terms of the educational concepts after consolidation; secondly, implementing the joint system. School teaching should be independent from the administrative management, thus to maintain New Asia's human spirit; thirdly, establishing an independent New Asia Institute, to continuously adopt Chinese traditional scholars' academic methods, thus to cultivate excellent students with general knowledge and noble personalities. Tang Junyi believed that human beings had a serious "materialized" trend in the modern age, and Chinese cultural spirit had started to decline since the Ming and Qing dynasties. Besides, he believed that there should be a mutual study relationship between Chinese traditional culture and Western culture. When Chinese people learned from the West, they should not forget and lose their traditional roots. From the merging of New Asia College into Chinese University of Hong Kong, it is clear of Tang Junyi's efforts in maintaining New Asia College's education ideals and carrying forward Chinese traditional cultural spirit.

\section{CONCLUSION}

"Moral Self" is the theoretical basis of Tang Junyi's educational thoughts, and all his views on education stemmed from his ideals to rebuild moral self. In order to achieve this ideal, Tang Junyi considered that education should promote the personality improvement both of educators and educatees. Higher-level education awareness fostered higher-level personalities while lower-level education awareness led to lower-level personalities. For educators, in the process of promoting the improvement of personality, they should not isolate themselves from educatees' daily lives, but go along with educatees' personalities as well as their mental and physical development. Our current school education, especially the humanistic education, is supposed to learn from the methods in New Asia College such as general education and tutorial system, but the most fundamentally, is to learn the essence of promoting the improvement of personality of both educators and educatees. Only the personality is improved, the moral self upward can be rebuilt, and the continuation of human cultural activities downwards can be achieved. 


\section{REFERENCES}

[1] Jin Xiaofang. The "Moral self" Concept in the Philosophy of Tang Junyi [J]. Confucius Research, 2009, 05: 44-51.

[2] Tang Junyi. Cultural Awareness and Moral Reason [M]. Beijing: China Social Sciences Publishing House, 2005, 10: 367, 367-371.

[3] Psychology Editorial Department in Chef Editor Committee of Encyclopedia of China. Encyclopedia of China (Psychology Volume) [M]. Beijing: Encyclopedia of China Publishing House, 1991: 370.

[4] Huaibin Jing. Confucian Personality Structure and Psychology Extension [J]. Modern Philosophy, 2007, 05: 48-56.

[5] Tang Junyi. Memories to Nanjing Central University [A]. Works Collection of Tang Junyi (Volume 9) [M]. Taiwan Student Book, 1991: 455-456.

[6] Mu Qian. Heritage of New Asia [M]. Beijing: Joint Publishing, 2006, 03: $1,2,12$.

[7] [9] Jin Xiaofang. Analysis on Educational Ideals of New Asia College and the Practice [J]. Education Review, 2009, 06: 139-141.

[8] [10] Tang Junyi. Re-understanding of Hope and Alertness and Aspiration [A]. Works Collection of Tang Junyi (Volume 9) [M]. Taiwan Student Book, 1991: 475-476. 